\title{
Pengendalian Persediaan Bahan Baku Impor dengan Menggunakan Metode EOQ Probabilistik pada Perusahaan Cat Industri
}

\author{
Ciswondo ${ }^{1}$, dan Anastasia Lidya Maukar ${ }^{2}$ \\ 1,2) Industrial Engineering Department, Faculty of Technology, President University \\ Jababeka Education Park, Jl. Ki Hajar Dewantara Kota Jababeka, Bekasi 17550, Indonesia \\ Email: ciswondo@gmail.com, almaukar@president.ac.id
}

\begin{abstract}
Abstrak
Penelitian ini dilakukan di sebuag perusahaan manufaktur yang memproduksi cat industri untuk genteng baja (roofing) dan dinding baja (walling). Tingkat penjualan cat industri sangat bervariasi dan fluktuatif tergantung demand produk dari customer. Akibat permintaan ynag fluktuatif dan metode peramalan terhadap permintaan produk saat ini kurang akurat yang hanya berdasarkan permintaan saru periode sebelumnya, maka persediaan (inventory) bahan baku impor belum optimal. Metode ARIMA digunakan untuk melakukan peramalan (forecasting) dan selanjutnya dilakukan pengendalian persediaan bahan baku impor dengan menggunakan metode Economic Order Quantity (EOQ) probabilistik untuk mengetahui jumlah pemesanan optimal, safety stock, re-order point dan frekuensi pemesanan sehingga dapat meminimalkan total inventory cost. Dengan metode EOQ probabilistik yang menerapkan adanya safety stock akan dapat meminimalkan resiko terjadinya kekurangan bahan baku import sehingga beban shortage cost pun dapat minimalkan. Dari hasil penelitian diketahui bahwa metode usulan memberikan penghematan total inventory cost sebesar Rp 493.832.731 atau diperoleh reduce cost sebesar 66\% dibandingkan metode perusahaan.
\end{abstract}

Kata kunci: Inventory, Forecasting, EOQ Probabilistik, Safety Stock, Re-Order Point, Total Inventory Costs.

\begin{abstract}
This research was carried out in a manufacturing company producing industrial paints for steel roofing and walling. The level of sales of industrial paint varies and fluctuates depending on product demand from customers. Due to fluctuating demand and forecasting methods for current product demand that is less accurate based only on demand from the previous period, the inventory of imported raw materials has not been optimal. The ARIMA method is used to forecast and then control imported raw material inventories using the probabilistic Economic Order Quantity (EOQ) method to determine the optimal order quantity, safety stock, re-order points and order frequency so as to minimize the total inventory cost. With the probabilistic EOQ method that implements the existence of safety stock will be able to minimize the risk of a shortage of imported raw materials so that the burden of shortage costs can be minimized. The results shows that the proposed method provides a total inventory cost savings of Rp.493,832,731 or obtained a $66 \%$ reduce cost compared to the company method
\end{abstract}

Keywords: Inventory, Forecasting, EOQ Probabilistik, Safety Stock, Re-Order Point, Total Inventory Costs.

\section{Pendahuluan}

Perusahaan manufaktur harus menerapkan sistem persediaan yang baik guna mengelola bahan baku (raw material) yang dibutuhkan untuk proses produksinya sehingga perusahaan dapat memenuhi semua permintaan pelanggan (customer). Fluktuasi permintaan dan ketersediaan bahan baku merupakan permasalahan umum dalam suatu sistem persediaan (inventory).

Kondisi permintaan produk yang bervariasi dan fluktuatif serta lead time bahan baku import yang lama akan menimbulkan variasi biaya yang harus dikeluarkan PT. XYZ sehingga perlu diantisipasi kemungkinan terjadinya kekurangan bahan baku (shortage) yang dapat berdampak langsung pada terhentinya proses produksi (stop line). Kekurangan bahan baku import ini memaksa PT. XYZ melakukan pengadaan bahan baku melalui jalur udara yang mengakibatkan kalkulasi harga bahan baku meningkat sebesar $60 \%$ dari harga normal. 
Pengelolaan bahan baku dengan menggunakan metode EOQ Probabilistik diharapkan bisa menjadi salah satu metode usulan bagi PT. XYZ dalam melakukan pengelolaan persediaan bahan baku. Dengan menerapkan metode persediaan tersebut akan dapat diketahui beberapa parameter dalam pengendalian persediaan bahan baku yang meliputi: jumlah pemesanan yang optimal, safety stock level, re-order point, persediaan maksimum, frekuensi pemesanan dan biaya total persediaan yang paling minimum.

\section{Studi Pustaka}

\subsection{Peramalan (Forecasting)}

Peramalan merupakan suatu perkiraan terhadap tingkat permintaan produk pada beberapa periode mendatang atau suatu proses yang dilakukan untuk memperoleh perkiraan kebutuhan produk di masa mendatang yang mencakup jumlah, waktu dan tempat dalam memenuhi permintaan terhadap barang maupun jasa (Nasution dan Prasetyawan, 1999). Sementara Tersine (1994) berpendapat bahwa peramalan merupakan suatu prediksi, proyeksi dan estimasi terhadap suatu kejadian atau aktivitas di masa mendatang yang masih belum pasti.

\subsubsection{Metode Deret Waktu (Time Series)}

Merupakan suatu metode yang dipergunakan untuk melakukan analisis serangkaian data terhadap fungsi waktu. Asumsi yang digunakan dalam metode time series yaitu beberapa pola data akan berulang sepanjang deret waktu, dimana pola data baru dapat diidentifikasi berdasarkan data historis. Dengan metode time series dapat dilihat variasi permintaan suatu produk pada waktu tertentu.

Untuk memilih salah satu metode deret waktu (time series) yang tepat yaitu dengan memperhatikan jenis atau bentuk pola data (Sumayang, 2003). Pola data terbagi menjadi empat yaitu: pola data horizontal, pola data musiman (seasonal), pola data trend dan pola data siklus (cycle).

\subsubsection{Metode ARIMA}

Menurut Iriawan dan Puji Astuti (2006), Autoregressive Integrated Moving Average (ARIMA) merupakan salah satu teknik peramalan dengan pendekatan deret waktu yang menggunakan teknik-teknik korelasi antar suatu deret waktu. Dasar pemikiran dari model ARIMA adalah pengamatan sekarang $\left(d_{t}\right)$ mempunyai ketergantungan pada satu atau beberapa pengamatan sebelumnya $\left(d_{t-k}\right)$. Dengan kata lain, model ini dibuat karena secara statistik ada korelasi (dependent) antar deret pengamatan. Untuk melihat adanya dependensi (ketergantungan) antar pengamatan dapat dilakukan uji korelasi antar pengamatan yang dikenal dengan Autocorrelation Function (ACF).

Tahapan awal model ARIMA adalah mengidentifikasi stasioneritas dari data baik dalam mean maupun variance. Apabila ditemukan data belum stasioner terhadap variance dilakukan upaya transformasi sedangkan apabila belum stasioner dalam mean dilakukan differencing (Suharjo, 2006)

\subsection{Persediaan (Inventory)}

Menurut Rangkuti (2004), persediaan adalah suatu aktiva perusahaan yang meliputi semua barang yang dimaksudkan untuk dijual pada periode usaha tertentu, atau persediaan barang-barang yang masih dalam pengerjaan atau proses produksi, ataupun persediaan bahan baku yang menunggu penggunaannya dalam suatu proses produksi.

Pengendalian persediaan adalah serangkaian kegiatan yang saling bertautan dalam suatu sistem produksi berdasarkan perencanaan yang meliputi waktu, kuantitas, kualitas dan biaya yang harus dikeluarkan perusahaan (Assauri, 2004).

Herjanto (1997) berpendapat bahwa persediaan mempunyai 6 (enam) fungsi penting guna memenuhi kebutuhan dalam perusahaan yaitu :

1. Meniadakan resiko terjadinya keterlambatan (delay) pengiriman barang yang dibutuhkan perusahaan.

2. Meniadakan resiko jika barang yang dipesan tidak bagus sehingga barang harus dikembalikan.

3. Meniadakan resiko terjadinya inflasi sehingga harga barang mengalami kenaikan.

4. Melakukan penyimpanan bahan baku yang hanya tersedia pada musim tertentu agar perusahaan tidak mengalami kekurangan ataupun kesulitan dalam memperoleh bahan baku di pasaran. 
5. Mendapatkan cash back atau keuntungan yang diperoleh karena melakukan pembelian bahan baku dalam jumlah tertentu (quantity discount).

6. Memberikan layanan kepuasan pelanggan dengan memastikan ketersediaan barang.

Persediaan diperlukan karena alasan empat faktor yaitu: faktor waktu tunggu (lead time), faktor ketidakpastian kedatangan bahan baku, faktor ketidakpastian penggunaan dalam proses produksi dan faktor ekonomis untuk mendapatkan biaya yang rendah (Yamit, 2005).

Menurut Matz (1994), manajemen persediaan yang efektif harus memenuhi beberapa hal berikut:

1. Dapat mencukupi kebutuhan bahan baku secara efisien agar sistem operasi berjalan lancar.

2. Dapat menyediakan stock bahan baku yang cukup guna mengantisipasi terjadinya kekurangan pasokan dan perubahan harga.

3. Dapat menyediakan bahan baku pada waktu yang tepat dengan biaya minimum serta kondisi penyimpanan bahan baku secara baik dan aman dari kemungkinan resiko kerusakan.

4. Dapat mengusahakan jumlah persediaan yang optimum untuk menghindari over stock yang tidak terpakai dan meminimalkan kerusakan barang dengan melakukan pemeriksaan secara sistematik.

5. Dapat memastikan kemandirian persediaan sehingga pengiriman produk ke pelanggan dapat dilakukan tepat waktu.

6. Dapat menjaga konsistensi jumlah modal yang dialokasikan dalam persediaan sesuai dengan perencanaan kebutuhan operasi.

\subsubsection{Metode EOQ Probabilistik}

Metode EOQ probabilistik memperhitungkan kemungkinan terjadinya stockout karena adanya penggunaan bahan baku yang tidak diharapkan atau waktu penerimaan yang lebih lama dari lead time yang ditentukan. Biaya yang dipertimbangkan dalam pengendalian persediaan dengan metode EOQ probabilistik meliputi: biaya pesan (ordering cost), biaya simpan (holding cost) dan biaya penundaan (back order cost).

Perhitungan pengendalian persediaan dengan metode EOQ probabilistik dilakukan dengan rumus berikut:

1. Jumlah pemesanan optimal

2. Jumlah back order

$$
Q^{*}=\sqrt{\frac{2 * C_{o} * D}{C_{C}}} * \sqrt{\frac{C_{C}+C_{s}}{C_{s}}}
$$

$$
\begin{aligned}
& S=Q^{*}-I \\
& I=\sqrt{\frac{2 * C_{o} * D}{C_{C}}} * \sqrt{\frac{C_{s}}{C_{C}+C_{s}}}
\end{aligned}
$$

3. Jumlah safety stock

$$
S S=k * \sigma L
$$

4. Waktu re-order point

$$
R=\bar{D} * L+S S
$$

5. Frekuensi Pemesanan

$$
\boldsymbol{f}=\frac{\boldsymbol{D}}{Q^{*}}
$$

6. Total annual holding cost

$$
C_{c}^{*}=\left(S S+\frac{\left(Q^{*}-S\right)^{2}}{2 * Q^{*}}\right) * C_{c}
$$

7. Total annual ordering cost

$$
\boldsymbol{C}_{\boldsymbol{o}}{ }^{*}=\left(\frac{\boldsymbol{D}}{\boldsymbol{Q}^{*}}\right) * \boldsymbol{C}_{\boldsymbol{o}}
$$

8. Total annual back order cost

$$
C_{s}^{*}=\frac{C_{s} * S^{2}}{2 * Q^{*}}
$$

9. Total inventory cost

$$
T C=C_{c}^{*}+C_{o}^{*}+C_{s}^{*}
$$

keterangan :

$\mathrm{Q}^{*} \quad$ : jumlah pemesanan optimal

$\mathrm{S}$ : jumlah back order

I : tingkat persediaan maksimum 


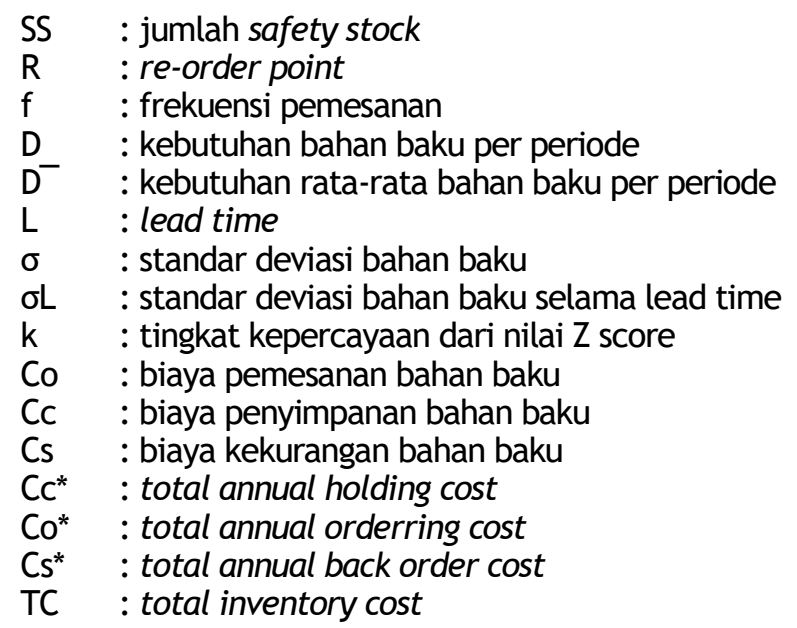

\section{Metodologi Penelitian}

\subsection{Tahap Observasi Awal}

Pada tahap ini dilakukan pengenalan dan pemahaman mengenai lingkungan perusahaan dengan melakukan survey lapangan pada PT. XYZ untuk mendapatkan informasi-informasi yang mendukung penelitian.

\subsection{Tahap Identifikasi dan Penelitian Awal}

Tahap identifikasi dan penelitian awal terdiri dari: latar belakang permasalahan yang dihadapi, rumusan masalah, tujuan penelitian serta studi pustaka.

\subsection{Tahap Pengumpulan Data}

Beberapa data yang digunakan untuk melakukan analisis masalah dalam penelitian ini merupakan data sekunder dari perusahaan yang meliputi :

a) Data penjualan cat industri periode tahun 2012 - 2015

b) Data tingkat pemenuhan order tahun 2014 dan 2015.

c) Frekuensi dan jumlah pembelian beberapa bahan baku import.

d) Biaya pembelian beberapa bahan baku import.

e) Lead time pengadaan bahan baku import.

\subsection{Tahap Pengolahan Data}

Pengolahan data yang dilakukan adalah melakukan peramalan (forecasting) terhadap permintaan cat industri beberapa bulan kedepan, perhitungan persediaan beberapa bahan baku import dengan menggunakan EOQ probabilistik guna menentukan jumlah pesanan yang optimal, safety stock, re-order point, back order dan frekuensi pemesanan, ordering cost, holding cost, back order cost, shortage cost serta total inventory cost.

\subsection{Tahap Analisis dan Interpretasi}

Hasil pengolahan data dari penelitian akan dibandingkan antara metode perusahaan sesuai data aktual lapangan dengan metode usulan dan selanjutnya dilakukan suatu evaluasi.

\subsection{Tahap Simpulan dan Saran}

Pada tahap ini berisi simpulan akhir berdasarkan penelitian yang telah dilakukan mengenai besarnya total biaya persediaan dan penghematan biaya persediaan yang diperoleh. Selain itu diberikan saran perbaikan yang berhubungan dengan penelitian demi perkembangan penelitian ini lebih lanjut.

\section{Hasil dan Diskusi}




\subsection{Analisis Kondisi Perusahaan Saat Ini}

\subsubsection{Data Tingkat Pemenuhan Order}

Tingkat pemenuhan order pada PT. XYZ dapat dilihat dari data persentase On Time In Full (OTIF) untuk pengiriman produk sesuai permintaan pesanan dari customer. Data OTIF pada PT. XYZ untuk periode tahun 2014 dan 2015 rata-rata berada pada level 95\% seperti ditunjukkan pada Gambar 1 dan Gambar 2.

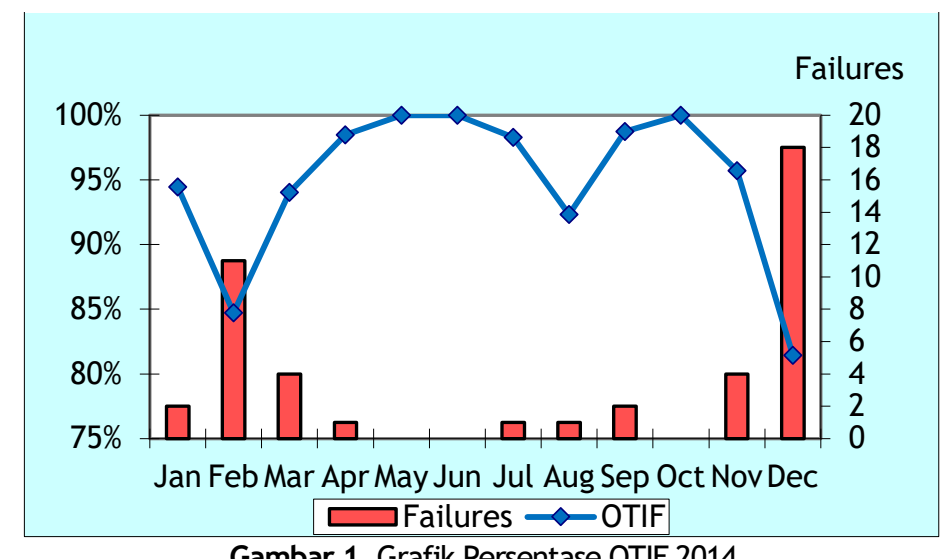

Gambar 1. Grafik Persentase OTIF 2014

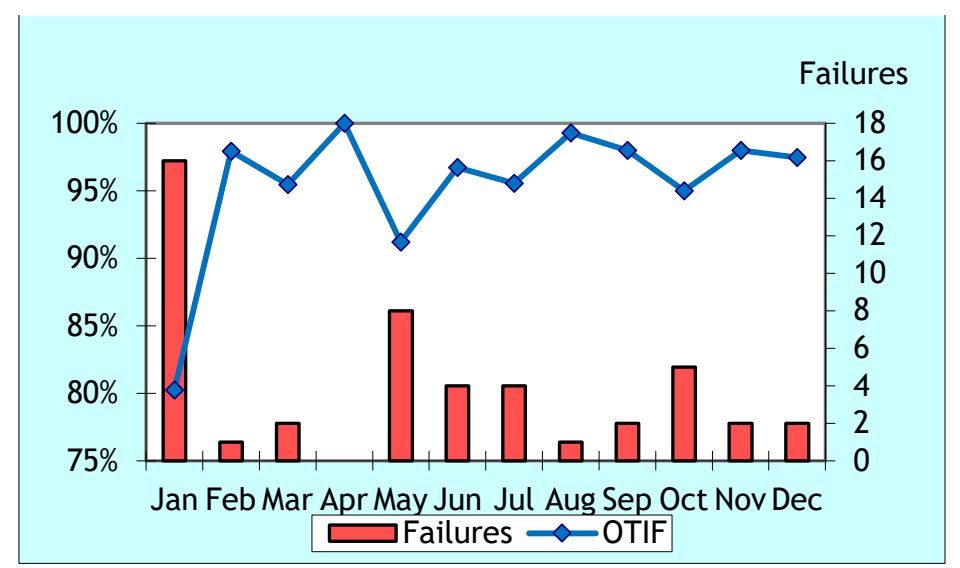

Gambar 2. Grafik Persentase OTIF 2015

\subsubsection{Data Penjualan (Sales Volume)}

Data historis jumlah penjualan (sales volume) selama 48 periode yaitu dari bulan Januari 2012 hingga hingga Desember 2015 akan dipergunakan untuk melakukan suatu sistem peramalan (forecasting) penjualan cat industri pada tahun 2016 sehingga dapat dilakukan perencanaan kebutuhan untuk beberapa bahan baku import. Data sales volume ditunjukkan pada Tabel 1.

Tabel 1. Sales Volume 2012- 2015

\begin{tabular}{|l|c|c|c|c|}
\hline \multirow{2}{*}{ Months } & \multicolumn{4}{|c|}{ Sales Volume (Ltrs) } \\
\cline { 2 - 5 } & $\mathbf{2 0 1 2}$ & $\mathbf{2 0 1 3}$ & $\mathbf{2 0 1 4}$ & $\mathbf{2 0 1 5}$ \\
\hline January & 95.621 & 86.880 & 64.505 & 85.160 \\
\hline February & 103.360 & 97.796 & 76.701 & 45.240 \\
\hline March & 109.020 & 102.240 & 75.340 & 54.024 \\
\hline April & 102.730 & 139.120 & 73.760 & 54.080 \\
\hline May & 141.520 & 93.410 & 74.938 & 87.000 \\
\hline June & 93.860 & 80.555 & 92.571 & 108.272 \\
\hline July & 102.500 & 149.050 & 78.841 & 107.380 \\
\hline August & 83.993 & 98.131 & 95.625 & 122.804 \\
\hline September & 98.921 & 101.500 & 141.139 & 108.120 \\
\hline October & 94.540 & 112.190 & 86.260 & 108.170 \\
\hline November & 90.300 & 117.100 & 93.740 & 91.740 \\
\hline December & 89.220 & 88.268 & 105.227 & 79.340 \\
\hline
\end{tabular}




\subsubsection{Komposisi dan Kebutuhan Bahan Baku Import}

Kebutuhan bahan baku untuk CG125, KC134, KS175, KS369 dan RN277 diperhitungkan dari persentase komposisi bahan baku untuk setiap tipe produk terhadap total jumlah penjualan periode 2015 yaitu sebesar 1.051.330 liter. Komposisi dan kebutuhan bahan baku import tahun 2015 ditunjukkan pada Tabel 2.

Tabel 2. Komposisi dan Kebutuhan Bahan Baku Import Tahun 2015

\begin{tabular}{|c|c|c|c|c|c|}
\hline No & $\begin{array}{c}\text { Bahan Baku } \\
\text { Import }\end{array}$ & $\begin{array}{c}\text { Komposisi } \\
(\%)\end{array}$ & $\begin{array}{c}\text { Kebutuhan } \\
(\mathrm{Kg} / \text { tahun) }\end{array}$ & $\begin{array}{c}\text { Pengadaan } \\
(\mathrm{Kg} / \text { tahun) }\end{array}$ & $\begin{array}{c}\text { Kekurangan } \\
(\mathrm{Kg} / \text { tahun) }\end{array}$ \\
\hline 1 & CG125 & 3,79 & 39.845 & 34.280 & 5.565 \\
\hline 2 & KC134 & 0,22 & 2.313 & 2.210 & 103 \\
\hline 3 & KS175 & 0,28 & 2.944 & 2.800 & 144 \\
\hline 4 & KS369 & 0,59 & 6.203 & 5.320 & 883 \\
\hline 5 & RN277 & 7,66 & 80.532 & 73.840 & 6.692 \\
\hline \multicolumn{2}{|c|}{ Total } & 12,54 & 131.837 & 118.450 & 13.387 \\
\hline
\end{tabular}

\subsubsection{Harga Bahan Baku dan Lead Tiem Pemesanan}

Harga pembelian beberapa bahan baku import dan lamanya waktu pemesanan (lead time) yang dibutuhkan untuk pengadaan bahan baku dari beberapa suplier dapat dilihat pada Tabel 3.

Tabel 3. Harga Bahan Baku Import dan Lead Time

\begin{tabular}{|c|c|c|c|c|}
\hline No & Bahan Baku & Supplier & $\begin{array}{c}\text { Lead Time } \\
\text { (hari) }\end{array}$ & $\begin{array}{c}\text { Harga per Kg } \\
\text { (Rp) }\end{array}$ \\
\hline 1 & CG125 & Lyond & 45 & 24.774 \\
\hline 2 & KC134 & Kings & 90 & 139.872 \\
\hline 3 & KS175 & Arkem & 90 & 131.433 \\
\hline 4 & KS369 & Allian & 45 & 39.247 \\
\hline 5 & RN277 & Chang & 15 & 23.521 \\
\hline
\end{tabular}

\subsubsection{Data Pembelian Bahan Baku}

Frekuensi pemesanan dan jumlah pengadaan beberapa bahan baku import untuk produksi cat industri yang dilakukan bagian procurement PT. XYZ selama periode tahun 2015 ditunjukkan pada Tabel 4.

Tabel 4. Data Pembelian Bahan Baku Import Tahun 2015

\begin{tabular}{|l|c|c|c|c|c|}
\hline $\begin{array}{c}\text { Periode } \\
\mathbf{2 0 1 5}\end{array}$ & $\begin{array}{c}\text { CG125 } \\
\mathbf{( K g )}\end{array}$ & $\begin{array}{c}\text { KC134 } \\
\mathbf{( K g )}\end{array}$ & $\begin{array}{c}\text { KS175 } \\
(\mathbf{K g})\end{array}$ & $\begin{array}{c}\text { KS369 } \\
(\mathbf{K g})\end{array}$ & $\begin{array}{c}\text { RN277 } \\
(\mathbf{K g})\end{array}$ \\
\hline Januari & 2.340 & 170 & 400 & 760 & 16.000 \\
\hline Februari & 2.340 & - & - & 760 & - \\
\hline Maret & 2.340 & 680 & 400 & - & - \\
\hline April & 2.340 & - & - & - & 3.120 \\
\hline Mei & 2.340 & - & 400 & - & 1.920 \\
\hline Juni & 2.340 & 680 & - & 760 & 2.880 \\
\hline Juli & 3.120 & - & - & 760 & 16.000 \\
\hline Agustus & 3.880 & - & 400 & - & - \\
\hline September & 3.120 & - & 400 & 760 & 1.920 \\
\hline Oktober & 3.120 & - & 800 & - & 16.000 \\
\hline November & 3.880 & 680 & - & 1.520 & 16.000 \\
\hline Desember & 3.120 & - & & - & - \\
\hline Total (Kg) & 34.280 & 2.210 & 2.800 & 5.320 & 73.840 \\
\hline Frekuensi (X) & 12 & 4 & 6 & 6 & 8 \\
\hline
\end{tabular}




\subsubsection{Biaya Pemesan dan Biaya Penyimpanan}

Perkiraan besarnya total biaya pemesanan yang dikeluarkan oleh PT. XYZ untuk beberapa bahan baku import tersebut adalah sebesar Rp 7.200.000 untuk sekali pemesanan yang dapat dilihat pada Tabel 5 .

Tabel 5. Biaya Pemesanan Bahan Baku

\begin{tabular}{|c|l|c|}
\hline No & \multicolumn{1}{|c|}{ Biaya } & Jumlah (Rp) \\
\hline 1 & Biaya telephon \& faximile & 300.000 \\
\hline 2 & Biaya dokumen (scan, copy, print) & 50.000 \\
\hline 3 & Biaya courier (JNE, Tiki) & 100.000 \\
\hline 4 & Biaya bea cukai & 6.750 .000 \\
\hline & Total Biaya Pemesanan & 7.200 .000 \\
\hline
\end{tabular}

Adapun perkiraan besarnya total biaya penyimpanan bahan baku import di PT. XYZ adalah sebesar 12\% per tahun dengan perincian yang ditunjukkan pada Tabel 6 .

Tabel 6. Biaya Rate Penyimpanan Bahan Baku

\begin{tabular}{|l|l|c|}
\hline No & Biaya & Persentase (\%) \\
\hline 1 & Bunga atas modal investasi & $11.25 \%$ \\
\hline 2 & Biaya gudang & $0.15 \%$ \\
\hline 3 & Biaya asuransi & $0.20 \%$ \\
\hline 4 & Biaya kerusakan bahan & $0.40 \%$ \\
\hline & Total Biaya Penyimpanan per tahun & $12 \%$ \\
\hline
\end{tabular}

\subsubsection{Biaya Pembelian Dan Biaya Kekurangan Bahan Baku Import}

Dalam kondisi normal PT. XYZ melakukan pengadaan bahan baku import melalui jalur laut (sea freight) sehingga biaya pembelian bahan baku lebih efisien. Bilamana terjadi kekurangan bahan baku untuk proses produksi maka PT. XYZ harus mengadakan pembelian bahan baku import secara mendadak dengan menggunakan sistem transportasi udara (air freight) untuk mempercepat lead time kedatangan bahan baku tersebut. Konsekuensi adanya pembelian bahan baku melalui air freight, perusahaan menanggung total biaya tambahan karena kekurangan bahan baku sebesar 60\% diatas harga bahan baku dengan pemesanan secara normal. Data besarnya biaya pembelian dan biaya kekurangan bahan baku import dapat dilihat pada Tabel 7.

Tabel 7. Biaya Pembelian dan Biaya Kekurangan Bahan Baku Tahun 2015

\begin{tabular}{|c|c|c|c|c|c|}
\hline $\begin{array}{c}\text { Bahan } \\
\text { Baku } \\
\text { (BB) }\end{array}$ & $\begin{array}{c}\text { Kebutuhan } \\
\text { (Kg/tahun) }\end{array}$ & $\begin{array}{c}\text { Jumlah } \\
\text { Pembelian } \\
\text { (Kg/tahun) }\end{array}$ & $\begin{array}{c}\text { Jumlah } \\
\text { Kekurangan } \\
\text { (Kg/tahun) }\end{array}$ & $\begin{array}{c}\text { Biaya Pembelian } \\
\text { (Rp) }\end{array}$ & $\begin{array}{c}\text { Biaya } \\
\text { Kekurangan } \\
\text { (Rp) }\end{array}$ \\
\hline CG125 & 39.845 & 34.280 & 5.565 & 848.224 .320 & 220.320 .576 \\
\hline KC134 & 2.313 & 2.210 & 103 & 309.117 .120 & 23.050 .906 \\
\hline KS175 & 2.944 & 2.800 & 144 & 368.012 .400 & 30.282 .163 \\
\hline KS369 & 6.203 & 5.320 & 883 & 208.794 .040 & 55.448 .162 \\
\hline RN277 & 80.532 & 73.840 & 6.692 & 1.736 .790 .640 & 251.844 .051 \\
\hline
\end{tabular}

\subsection{Peramalan Penjualan dengan Metode ARIMA}

\subsubsection{Plot Data Penjualan}

Langkah awal yang harus dilakukan dalam peramalan model ARIMA yaitu membuat plot data asli dan analisis trend data volume penjualan cat industri. Plot data dan trend data ini akan menunjukkan apakah data penjualan tersebut sudah stasioner. Gambar 3 merupakan grafik trend analysis data penjualan, dimana masih terlihat bahwa data tersebut belum stasioner terhadap mean (nilai rata-rata) karena data menunjukkan adanya trend penurunan sepanjang sumbu $X$. Oleh karena data masih belum stasioner maka harus dilakukan proses differencing (pembedaan) untuk membuat data menjadi stasioner. 


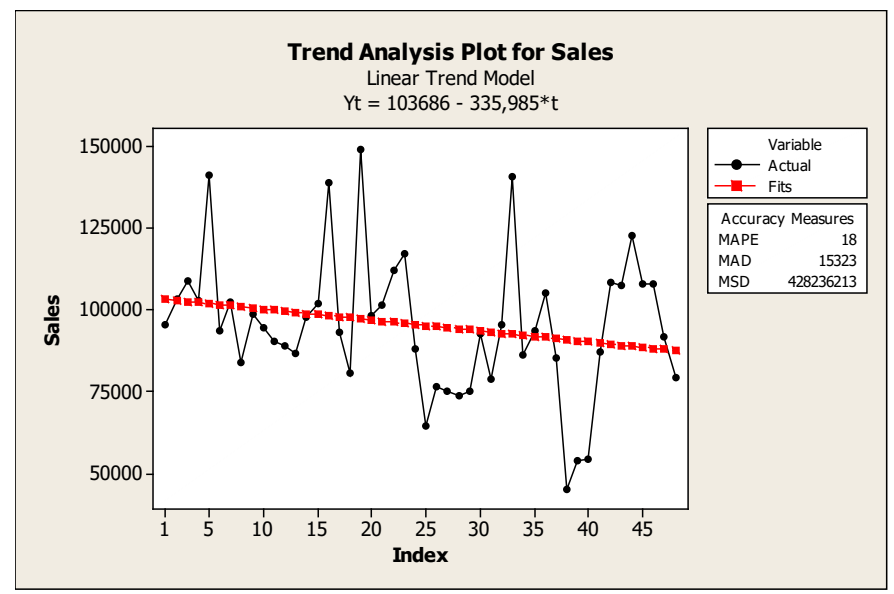

Gambar 3. Grafik Trend Data Volume Penjualan

\subsubsection{Proses Differencing Data Penjualan}

Data penjualan yang digunakan dalam penelitian belum stasioner dan harus dilakukan dua kali proses differencing hingga data menjadi stasioner terhadap mean yaitu tidak menunjukkan adanya suatu trend dimana data bergerak disekitar mean (nilai rata-rata) dan jarak antar plot data juga sudah homogen yang ditunjukkan pada Gambar 4.

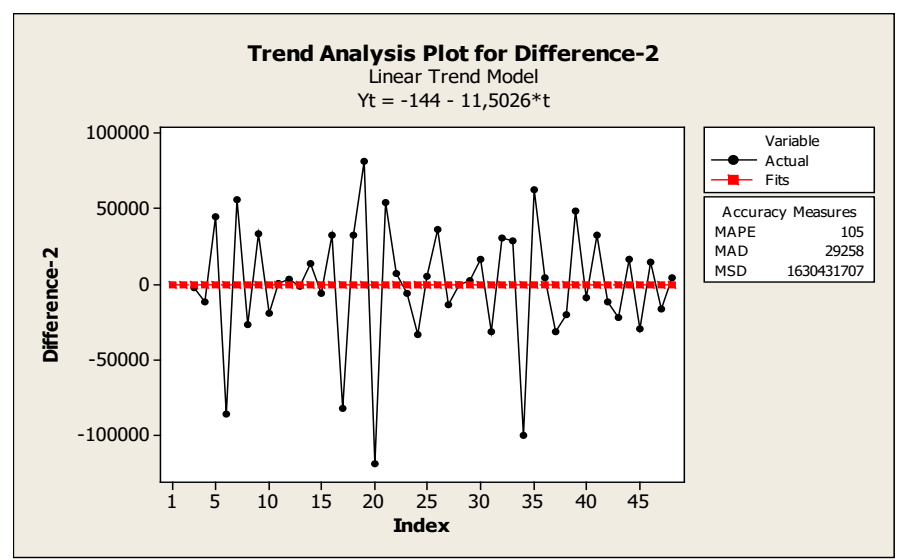

Gambar 4. Trend Data Difference-2

\subsubsection{Proses Transformasi (Transformation)}

Proses transformasi diperlukan utuk memastikan bahwa data penjualan yang digunakan sudah stasioner dalam varians dengan menggunakan Box-Cox plot. Data penjualan ini memerlukan dua kali transformasi agar data tersebut stasioner dalam varians, dimana diperoleh nilai rounded-value $>1$ seperti yang ditunjukkan pada Gambar 5.

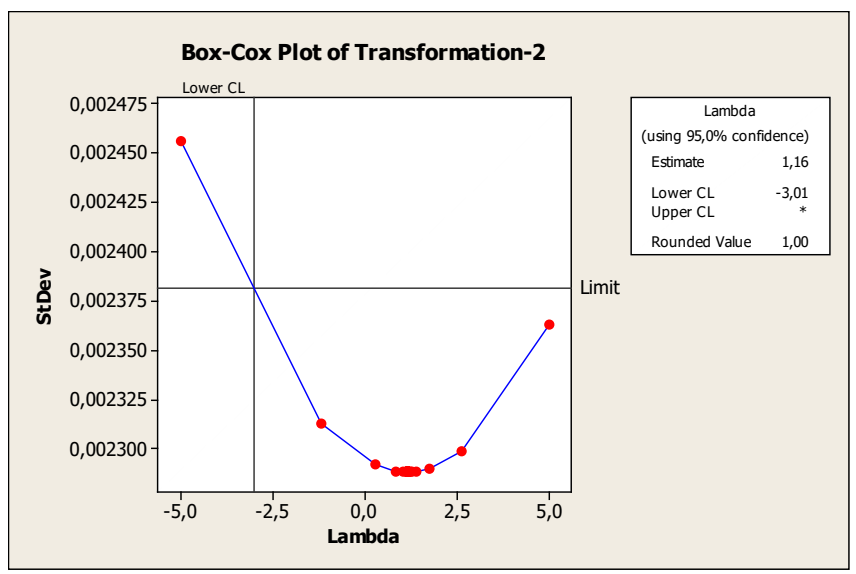

Gambar 5. Grafik Box-Cox Plot Transformation-2 


\subsubsection{Uji Korelasi Data Penjualan}

Berdasarkan correlogram autokorelasi yang ditunjukkan pada Gambar 6. terlihat bahwa nilai autokorelasi data hasil difference-2 kurang dari $\pm 0,5$ sehingga dapat dikatakan data tersebut stasioner, dimana nilainya tidak berbeda secara signifikan pada time lag ke-1 sehingga diperoleh dugaan data dipengaruhi oleh parameter MA(1).

Berdasarkan correlogram autokorelasi parsial yang ditunjukkan pada Gambar 7. terlihat bahwa nilai autokorelasi parsial data hasil difference-2 juga kurang dari $\pm 0,5$ sehingga dapat dikatakan data tersebut stasioner. Nilai autokorelasi parsial tidak signifikan pada time lag ke-1 sehingga diperoleh dugaan data dipengaruhi oleh parameter AR(1).

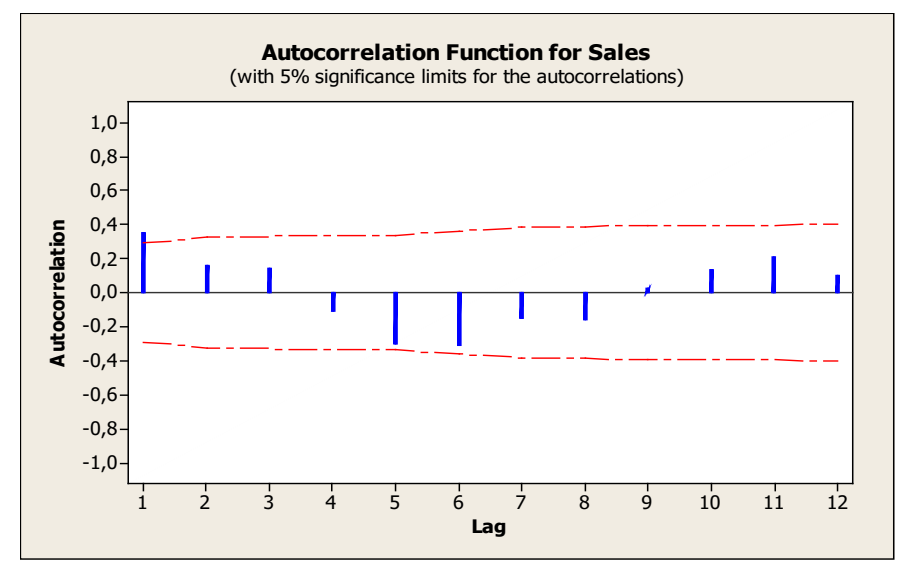

Gambar 6. Grafik Fungsi Autokorelasi (ACF)

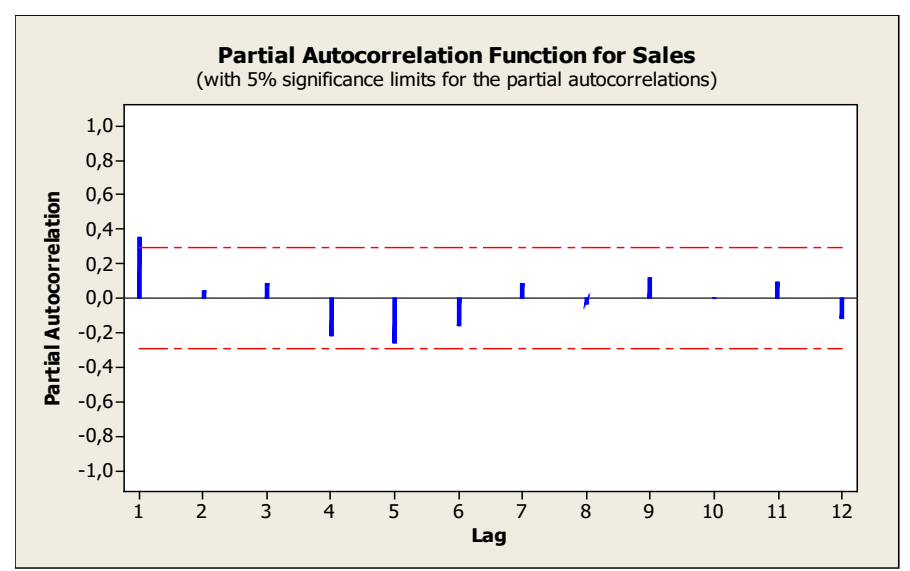

Gambar 7. Grafik Fungsi Autokorelasi Parsial (PACF)

\subsubsection{Uji Asumsi Residual (Diagnostic Checking)}

Diagnostic checking atau uji asumsi residual merupakan pengujian kelayakan model yang dapat dilihat berdasarkan grafik ACF (Autocorrelation Function) dan PACF (Partial Autocorrelation Function) dari residuals. Hasil uji asumsi residual dari data penjualan ditunjukkan pada Gambar 8 dan Gambar 9. 


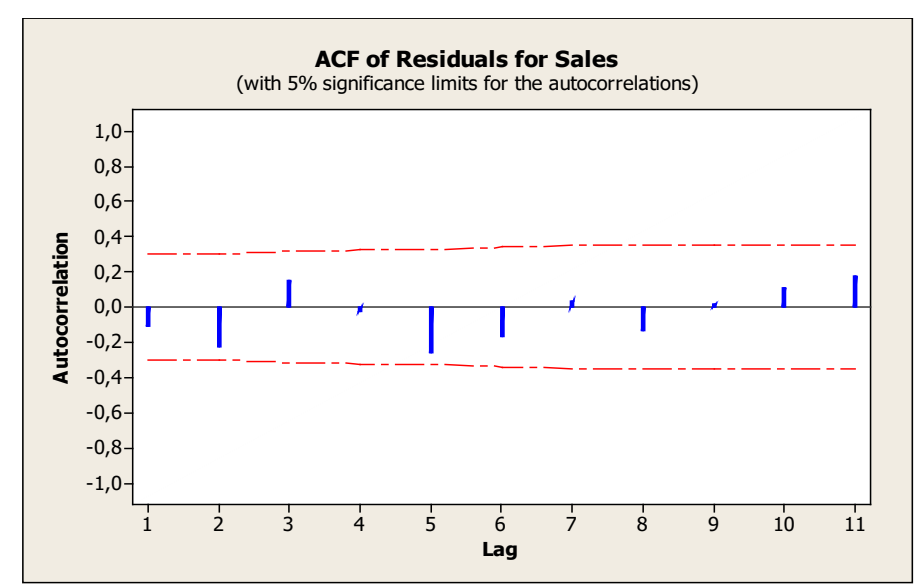

Gambar 8. Grafik ACF of Residuals

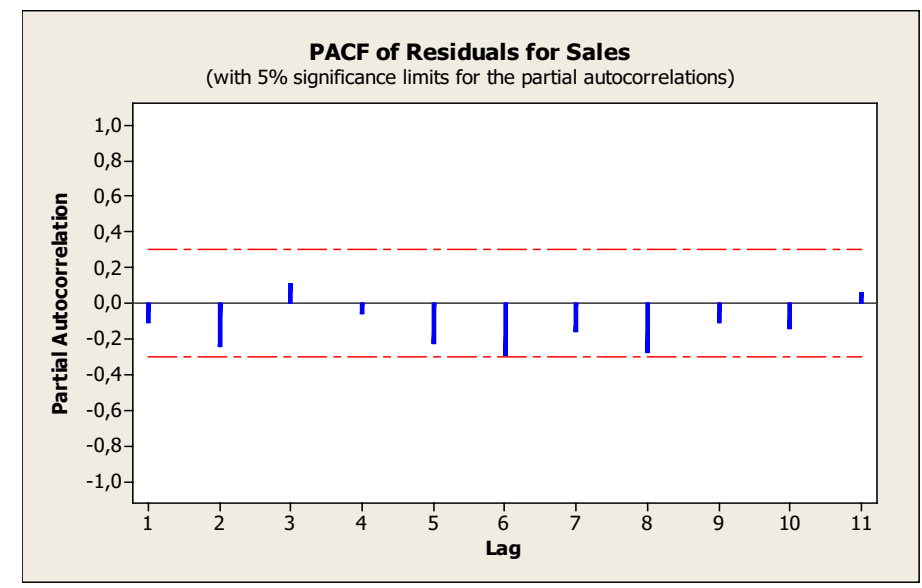

Gambar 9. Grafik PACF of Residuals

\subsubsection{Uji Normalitas Residual}

Uji normalitas residual dari data peramalan dengan menggunakan tingkat kepercayaan $\alpha=0,05$ dimana uji normalitas yang digunakan adalah metode Kolmogorov Smirnov (KS).

Hipotesa yang digunakan untuk uji normalitas dalam penelitian ini yaitu, jika :

- $\mathrm{H}_{0} \quad$ : error data/residual berdistribusi normal

- $\mathrm{H}_{1}$ : error data/residual tidak berdistribusi normal Jika $\mathrm{p}$-value > a maka $\mathrm{H}_{0}$ gagal ditolak.

Nilai Kolmogorov Smirnov (KS) dari hasil uji normalitas berada di atas a $(0,05)$ yaitu sebesar 0,118 yang berarti tidak terdapat perbedaan yang signifikan antara data yang diuji dengan data normal baku, serta $p$ value mempunyai nilai lebih dari 0,05 yaitu sebesar 0,094 sehingga menerima $\mathrm{H}_{0}$ dan residual dapat dinyatakan telah terdistribusi secara normal.

\subsection{Analisis Persediaan Bahan Baku Tahun 2015 dengan Metode EOQ Probabilistik}

Dengan menerapkan metode pengendalian persediaan bahan baku model EOQ probabilistik, maka total biaya persediaan (total inventory cost) pada tahun 2015 untuk bahan baku CG125, KC134, KS175, KS369 dan RN277 adalah sebesar Rp 255.726.938 seperti ditunjukkan pada Tabel 8. 
Tabel 8. Perhitungan Persediaan Bahan Baku Tahun 2015 dengan Metode EOQ Probabilistik

\begin{tabular}{|l|l|c|c|c|c|c|c|}
\hline \multirow{2}{*}{ No } & Faktor Pengendalian & \multirow{2}{*}{ Simbol } & \multicolumn{5}{|c|}{ Model EOQ Probabilistik } \\
\cline { 5 - 8 } & Persediaan & & CG125 & KC134 & KS175 & KS369 & RN277 \\
\hline 1 & Jumlah Pesanan Optimal (kg) & $Q^{*}$ & 14.416 & 1.461 & 1.700 & 4.515 & 21.014 \\
\hline 2 & Safety Stock (kg) & $S S$ & 9.111 & 528 & 673 & 1.419 & 4.604 \\
\hline 3 & Frekuensi Pemesanan (kali) & $f$ & 3 & 2 & 2 & 2 & 4 \\
\hline 4 & Re-order point (kg) & $R$ & 15.751 & 1.101 & 1.163 & 2.453 & 7.960 \\
\hline 5 & Back order (kg) & $C_{s}$ & 1.001 & 102 & 118 & 313 & 1.455 \\
\hline 6 & Total Biaya Pesan (Rp) & $C_{\sigma}^{*}$ & 19.900 .389 & 11.398 .768 & 12.468 .706 & 9.891 .827 & 27.592 .576 \\
\hline 7 & Total Biaya Simpan (Rp) & $C_{c}^{*}$ & 56.650 .756 & 23.097 .177 & 26.577 .323 & 18.629 .695 & 44.011 .620 \\
\hline 8 & Total Biaya Back order (Rp) & $C_{s}^{*}$ & 1.375 .875 & 796.839 & 861.212 & 681.281 & 1.792 .894 \\
\hline & Total Inventory cost (Rp) & $T C$ & 77.297 .020 & 35.292 .784 & 39.907 .241 & 29.202 .803 & 73.397 .090 \\
\hline & Grand Total Inventory cost (Rp) & $\sum_{T C}$ & & & 255.726 .938 & & \\
\hline
\end{tabular}

\subsection{Analisis Persediaan Bahan Baku Tahun 2015 dengan Metode Perusahaan}

Dari hasil analisis perhitungan persediaan metode perusahaan untuk bahan baku CG125, KC134, KS175, KS369 dan RN277 maka dapat diketahui bahwa total biaya persediaan (total inventory cost) sebesar Rp 734.533.576 seperti ditunjukkan pada Tabel 9.

Tabel 9. Perhitungan Persediaan Bahan Baku Tahun 2015 dengan Metode Perusahaan

\begin{tabular}{|c|l|c|c|c|c|c|c|}
\hline \multirow{2}{*}{ No } & \multirow{2}{*}{$\begin{array}{l}\text { Faktor Pengendalian } \\
\text { Persediaan }\end{array}$} & \multirow{2}{*}{ Simbol } & \multicolumn{5}{|c|}{ Model Persediaan PT. XYZ } \\
\cline { 5 - 8 } & & CG125 & KC134 & KS175 & KS369 & RN277 \\
\hline 1 & Jumlah Pesanan Optimal (kg) & $Q^{*}$ & - & - & - & - & - \\
\hline 2 & Safety Stock (kg) & $S S$ & - & - & - & - & - \\
\hline 3 & Frekuensi Pemesanan (kali) & $f$ & 12 & 4 & 6 & 6 & 8 \\
\hline 4 & Re-order point (kg) & $R$ & - & - & - & - & - \\
\hline 5 & Back order (kg) & $C_{s}$ & - & - & - & - & - \\
\hline 6 & Total Biaya Pesan (Rp) & $C_{o}^{*}$ & 19.900 .389 & 11.398 .768 & 12.468 .706 & 9.891 .827 & 27.592 .576 \\
\hline 7 & Total Biaya Simpan (Rp) & $C_{c}^{*}$ & 21.400 .552 & 12.261 .443 & 13.406 .200 & 10.632 .825 & 29.661 .261 \\
\hline 8 & Total Biaya Shortage (Rp) & $C_{s}^{*}$ & 220.320 .576 & 23.050 .906 & 30.282 .163 & 55.448 .162 & 251.844 .051 \\
\hline & Total Inventory cost (Rp) & $T C$ & 261.621 .517 & 46.711 .117 & 56.157 .069 & 75.972 .814 & 309.097 .888 \\
\hline & Grand Total Inventory cost(Rp) & $\sum_{T C}$ & & & 749.560 .405 & & \\
\hline
\end{tabular}

\subsection{Perhitungan Kebutuhan Bahan Baku Periode Januari - Juni 2016}

Dengan menerapkan metode pengendalian persediaan bahan baku model EOQ probabilistik, maka total biaya persediaan (inventory cost) untuk bahan baku CG125, KC134, KS175, KS369 dan RN277 periode Januari Juni 2016 adalah sebesar Rp 115.112.793 seperti ditunjukkan pada Tabel 10. 
Tabel 10. Total Inventory Cost Periode Januari - Juni 2016 dengan Metode EOQ Probabilistik

\begin{tabular}{|c|c|}
\hline Bahan Baku & EOQ Probabilistik \\
\hline CG125 & 28.901 .831 \\
\hline KC134 & 16.385 .841 \\
\hline KS175 & 17.567 .166 \\
\hline KS369 & 13.825 .906 \\
\hline RN277 & 38.432 .049 \\
\hline Total Inventory Cost (IDR) & 115.112 .793 \\
\hline
\end{tabular}

\subsection{Interpretasi Hasil}

Berdasarkan hasil perhitungan pengendalian persediaan tahun 2015 pada kelima bahan baku import, yaitu: CG125, KC134, KS175, KS369 dan RN277 maka diperoleh perbandingan total inventory cost antara metode EOQ probabilistik sebagai metode usulan dengan metode perusahaan pada saat ini yang ditunjukkan pada Tabel 11 dan Gambar 10.

Tabel 11. Perbandingan Total Inventory Cost Tahun 2015

\begin{tabular}{|c|c|c|c|}
\hline Bahan Baku & Metode Perusahaan (Rp) & EOQ Probabilistik (Rp) & Reduce Cost (Rp) \\
\hline CG125 & 261.621 .517 & 77.927 .020 & 183.693 .761 \\
\hline KC134 & 46.711 .117 & 35.292 .784 & 11.418 .333 \\
\hline KS175 & 56.157 .069 & 39.907 .241 & 16.249 .828 \\
\hline KS369 & 75.972 .814 & 29.202 .803 & 46.770 .011 \\
\hline RN277 & 309.097 .888 & 73.397 .090 & 235.700 .798 \\
\hline Total Cost & $\mathbf{7 4 9 . 5 6 0 . 4 0 5}$ & $\mathbf{2 5 5 . 7 2 6 . 9 3 8}$ & 493.833 .467 \\
\hline
\end{tabular}

Tabel 11. menunjukkan adanya penurunan biaya (reduce cost) yang dihasilkan dengan metode EOQ probabilistik yaitu sebesar Rp 493.833.467 dengan tingkat persentase yang cukup signifikan yaitu sebesar $66 \%$.

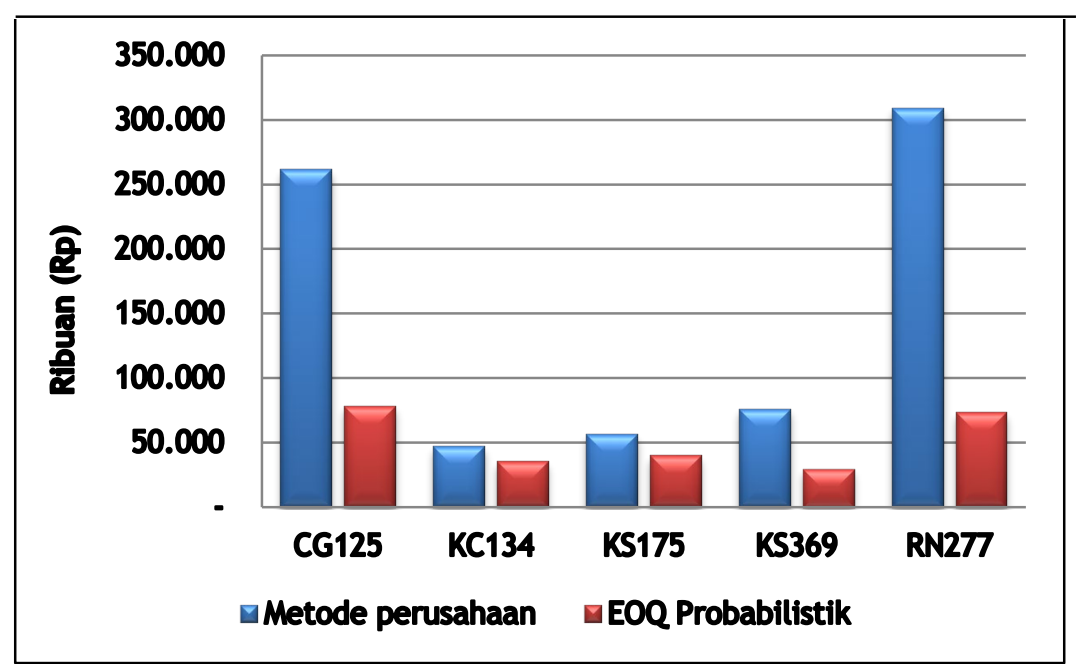

Gambar 10. Grafik Perbandingan Total Inventory Cost Tahun 2015

\section{Simpulan}

Pengendalian persediaan bahan baku dengan menggunakan metode EOQ probabilistk berdasarkan peramalan model ARIMA $(1,2,1)$ untuk beberapa bahan baku import tahun 2015 pada PT. XYZ dapat menghasilkan penghematan biaya (cost saving) hingga mencapai 66\% yaitu sebesar Rp 493.833 .467 dibandingkan metode perusahaan saat ini. 
Berdasarkan analisis yang telah dilakukan maka diberikan saran agar penelitian mengenai pengendalian persediaan bahan baku ini dapat dilanjutkan dengan menggunakan model persediaan probabilistik lainnya sehingga dapat diperoleh model persediaan yang paling tepat.

\section{Daftar Pustaka}

1. Assauri, Sofjan, (2004). Manajemen Produksi dan Operasi, Edisi Revisi. Jakarta: Lembaga Penerbit Fakultas Ekonomi UI,

2. Herjanto, Eddy, (2008). Manajemen Produksi dan Operasi, Edisi Ketiga. Jakarta: PT. Grasindo.

3. Iriawan, Nur dan Puji Astuti, Septin. (2006). Mengolah Data Statistik dengan Mudah Menggunakan Minitab 14. Yogyakarta: Andi.

4. Matz, Adolph. Akuntansi Biaya Perencanaan dan Pengendalian, Jilid I. Jakarta: Erlangga, 1994.

5. Nasution, Arman Hakim dan Prasetyawan, Y.P. (1999). Perencanaan dan Pengendalian Produksi, Edisi Revisi. Yogyakarta: Graha Ilmu.

6. Rangkuti, Freddy,(2004). Manajemen Persediaan: Aplikasi di Bidang Bisnis. Jakarta: Grafindo Persada,

7. Suharjo, Bambang. Analisis Regresi Terapan dengan SPSS. Yogyakarta: Graha Ilmu, 2006.

8. Sumayang, L. Dasar-dasar Manajemen Produksi dan Operasi. Jakarta: Salemba Empat,

9. Tersine, R. J. Principles of Inventory and Material Management. New Jersey: Prentice Hall, 1994.

10. Yamit, Zulian. Manajemen Persediaan, Edisi Pertama. Yogyakarta: Ekonosia, 2005. 